\title{
Spatial agency bias and word order flexibility: A comparison of 14 European languages
}

\author{
Caterina Suitner $^{1 \star *}\left(\mathbb{D}\right.$, Anne Maass $^{1}$ (D), Eduardo Navarrete ${ }^{1}\left(\mathbb{D}\right.$, Magdalena Formanowicz $^{2}$ (D), \\ Boyka Bratanova $^{3}$, Carmen Cervone ${ }^{1}$ (D), Juho Eemeli Hakoköngäs ${ }^{4}$ (D), Toon Kuppens ${ }^{5}$, \\ Eleni Lipourli ${ }^{6}$, Tamara Rakić ${ }^{7}$, Andrea Scatolon ${ }^{8}$ (D) Catia P. Teixeira ${ }^{5}$, Zhenlan Wang ${ }^{9}$ (D), \\ Maria Pedro Sobral ${ }^{10}$ and Antonin Carrier ${ }^{11}$ \\ ${ }^{1}$ Center for Research on Social Relations, SWPS University of Social Sciences and Humanities in Warsaw, \\ ${ }^{2}$ University Social Sciences and Humanities, Warsaw, Poland, ${ }^{3}$ University of St. Andrews, ${ }^{4}$ University of \\ Helsinki, ${ }^{5}$ University of Groningen, ${ }^{6}$ University of the Aegean, ${ }^{7}$ Lancaster University, ${ }^{8}$ University of Trento, \\ ${ }^{9}$ New School for Social Research, ${ }^{10}$ Universidade do Porto and ${ }^{11}$ Université de Bordeaux \\ *Corresponding author. E-mail: caterina.suitner@unipd.it.
}

(Received 20 March 2019; revised 23 September 2020; accepted 02 November 2020; first published online 10 February 2021)

\begin{abstract}
The spatial agency bias predicts that people whose native language is rightward written will predominantly envisage action along the same direction. Two mechanisms contribute jointly to this asymmetry: (a) an embodied process related to writing/reading; (b) a linguistic regularity according to which sentence subjects (typically the agent) tend to precede objects (typically the recipient). Here we test a novel hypothesis in relation to the second mechanism, namely, that this asymmetry will be most pronounced in languages with rigid word order. A preregistered study on 14 European languages $(n=420)$ varying in word order flexibility confirmed a rightward bias in drawings of interactions between two people (agent and recipient). This bias was weaker in more flexible languages, confirming that embodied and linguistic features of language interact in producing it.
\end{abstract}

Keywords: cross-linguistic; spatial agency bias; word order

According to the spatial agency bias (SAB) model, people envisage human action to evolve in line with writing direction, for instance from left to right among English or Italian speakers and from right to left among Arabic or Farsi speakers. Agency maps onto the horizontal trajectory that people perform while writing or reading. By extension, people envisage agentic individuals and groups (e.g., men or young people) to be positioned on the left, acting rightward (for an overview, see Suitner \& Maass, 2016). Although spatial asymmetries are generally of small magnitude, they are very pervasive, affecting, among others, drawing and imagining (Maass, Suitner, Favaretto, \& Cignacchi, 2009), the symbolic representation of agency, the

(C) The Author(s), 2021. Published by Cambridge University Press. This is an Open Access article, distributed under the terms of the Creative Commons Attribution licence (http://creativecommons.org/licenses/by/4.0/), which permits unrestricted re-use, distribution, and reproduction in any medium, provided the original work is properly cited. 
categorization of males versus females, and judgments of authenticity of photographs (Suitner, Maass, \& Ronconi, 2017).

\section{Mechanisms Driving the SAB}

According to the SAB model, this asymmetry is the joint function of two processes. The first is an embodied process derived from the asymmetrical motor activity involved in handwriting and the equally asymmetrical visual scanning involved in reading. Both activities are performed repeatedly in people's daily lives, and this habitual hand and eye movement provides the trajectory for agency to map onto (e.g., rightward in languages that use the Latin script and leftward in languages that use the Arabic script). Support for the first (embodied) mechanism comes from numerous studies comparing left-to-right versus right-to-left written languages, where the $\mathrm{SAB}$ follows the predominant writing direction (e.g., Maass, et al., 2009; Maass, Suitner, \& Nadhmi, 2014), even when depicting static objects from auditory inputs (Román, Fathi, \& Santiago, 2013). This effect of script directionality emerges also in activities that require little mental imagery, such as line bisection tasks (Chokron, \& Imbert, 1993) or straight head pointing (Kazandjian et al., 2009).

However, embodiment alone is unable to explain the SAB, unless one assumes that the agent is generally positioned where language starts (i.e., left for languages such as English or Italian, and right for languages such as Urdu or Hebrew), whereas the recipient is mentioned subsequently. Hence, the second mechanism necessary for the SAB phenomena to emerge refers to the canonical word order of subject and object in a given language. According to the World Atlas of Languages, in $83 \%$ of the languages analyzed so far, the subject precedes the object in standard active sentences (Dryer, 2013; also Hawkins, 1983). Only in 3\% of the languages (e.g., in Malagasy, Chuj, and Cubeo) the canonical order reverses, with the object preceding the subject. The remaining $14 \%$ of languages are classified as lacking a dominant order.

Evidence supporting this second mechanism is much more limited, as languages with object-subject order are rare and generally spoken by small language communities. The one exception is a study comparing Malagasy speakers (a language written from left to right, but with object-subject order) with Italian and Arabic speakers (Maass et al., 2014). Participants in this study performed two tasks: a drawing task in which they had to represent two human interactions (aggression and exchange of a gift); and a picture-matching task in which they had to choose between two mirror images (agent to left vs. agent to right) the one that best represented a given statement (e.g., The father caresses the child). Whereas Italian participants showed a robust rightward bias and Arabic participants a robust leftward bias across the two tasks, Malagasy speakers showed an unstable pattern. When word order was not salient (drawing of an aggression or gift giving) the embodied process prevailed, resulting in a rightward bias. When word order was salient (picture-matching task), participants showed a leftward bias. This suggests that, for the $\mathrm{SAB}$ to emerge, the two processes have to be congruent. However, given the limited empirical support for the role of word order, additional evidence is needed before clear conclusions can be drawn. One way to investigate the role of word order in the $\mathrm{SAB}$ is to compare languages that have a very rigid word order with those that are more flexible, as will be explained in the next section. 


\section{Word Order Flexibility}

Theoretically, word order flexibility can be examined both from a grammatical and from a pragmatic perspective. Grammatically, languages may have one, multiple, or no predominant word order for specific elements, and they may allow deviations from dominant word orders to different degrees (e.g., Siewierska, Rijkhoff, \& Bakker, 2010). In contrast, a pragmatic approach focuses on the principles that motivate word order variation in written or spoken language and on the communication goals it serves (e.g., Payne, 1992; Sornicola, 2006). To our knowledge, whereas languages have been classified according to the dominant syntactic order, there is currently no classification of word order flexibility in spoken or written language. We therefore focus on the grammatical aspect of word order flexibility and propose that word order flexibility in mentioning the agent before the recipient is a core component of the SAB.

We test the same general idea developed by Maass et al. (2014) from a different perspective and with a larger sample of languages. We focus on languages that share the same writing direction (from left to right) and the same canonical order (subject and verb preceding the object), but that allow different degrees of freedom to deviate from that order. We argue that, if word order is an essential mechanism of the SAB, then languages with a more flexible word order should produce smaller SABs. There are different language characteristics that allow for greater flexibility in word order. Such characteristics include the presence of cases, the person-number agreement, and the possibility to drop the subject or the pronoun, which are the characteristics considered in the present research.

As far as cases are concerned, take the example of Latin and Russian, on the one hand, and English, on the other. In all of these languages, the subject precedes the object in the dominant order; however, they differ in word order flexibility. On the one hand, in Latin many grammatical and syntactic features (person, gender, number, case, tense, and voice) are communicated through suffixes. Verbs, nouns, adjectives, and pronouns are inflected to mark grammatical functions through conjugation (verbs) and declension (nouns, adjectives, and pronouns). For instance, a noun's syntactic role in the sentence is marked by different suffixes corresponding to seven different cases (nominative, genitive, dative, accusative, ablative, vocative, and locative). Similarly, the statement Laura deceives Mark in Russian becomes Лаура (Laura) обманывает (deceives) Марка (Mark). Here Лаура (Laura) as the subject takes the nominative case, whereas Мapк (Mark) as the object takes suffix $a$ (Марка). In this case, it becomes irrelevant whether the sentence is written as Лаура обманьвает Марка, аs Марка обманывает Лаура, or as Обманывает Лаура Марка, because the role of subject versus object is unambiguously defined by the suffix. This warrants maximal freedom in word order given that subject and object can be identified regardless of their position. Not surprisingly, then deviations from the standard subject-object-verb order in Latin and in Russian are particularly likely to be tolerated (Bakker, 2010). In languages such as English, on the other hand, because of the lack of case marking for nouns, word order is often the only way to define subject versus object roles (e.g., Laura deceives Mark), and, hence, the canonical subject-verb-object order is applied in a rather rigid way. Case marking is, therefore, the first feature that allows a less rigid ordering of agent-recipient; if 
thematic roles are explicitly marked, their identification will not need to rely as much on word order (Primus, 1998).

Person-number agreement is another key feature that allows the disambiguation of thematic roles, and has previously been associated to dislocation (Chomsky, 1995). According to Rizzi (1986), languages can be differentiated by their intensity of agreement. An example of rich agreement languages is Italian, as it is characterized by distinct morphological forms for different persons, numbers, and genders. In Italian one can say Preoccupata guardò la figlia i genitori, or Preoccupati guardarono la figlia i genitori, which in English would be Worried, the daughter watched the parents (first sentence) and Worried, the parents watched the daughter (second sentence). However, a literal translation would in both cases be worried watched the daughter the parents. In Italian, the subject of the first sentence is figlia (the daughter); therefore, preoccupata (worried) and guardo (watched) have to take the morphological form that agrees with figlia (viz. feminine and singular). In the second sentence where the subject is genitori (the parents), the same words worried and watched take the morphological form that agrees with genitori, namely, preoccupati and guardarono. Once the morphological agreement between nouns, verb, and adjective is provided, the word order does not influence the thematic meaning of the sentence. In the Italian example, thematic roles identification is not strictly related to word order. In line with Chomsky (1981), the core idea is that overt agreement signals thematic roles, so that the subject can be moved or even dropped, as the deletion is recoverable.

Some languages allow us to drop the subject or pronoun altogether (as in he passes the gift to Mary) because the verb inflection contains information about person, number, and/or gender. Null-subject and pronoun-drop languages therefore allow the identification of the involved agents without necessarily mentioning them explicitly. Of course, when the subject is not explicitly mentioned nor is the order. Consequently, ordering effects are expected to be mitigated when pronouns or the subject can be omitted as this indicates that the language does not rely so much on order for disambiguating thematic roles. Together, we argue that word order flexibility will be greater in languages that have noun cases, rich agreement, subject drop, and/or pronoun drop.

Given that there are systematic differences across languages in word order flexibility, one may hypothesize that the $\mathrm{SAB}$ will be most pronounced when flexibility is low; that is, in languages where the subject generally precedes the object and this canonical word order is applied very rigorously. Readers and writers of such languages encounter the subject-object order in active sentences almost without exception; combined with a rightward script, this will lead them to develop a consistent mental representation of action as flowing from left to right. In contrast, readers and writers of more flexible languages are less likely to develop such a well-defined asymmetrical scheme of action. Thus, our first goal was to test the prediction that participants speaking languages characterized by a rigid syntax are more likely to place the agent to the left of the recipient compared to participants speaking a language with higher word order flexibility.

To our knowledge, a ranking of word order flexibility that focuses specifically on thematic roles or on the flexibility of subject/object positioning is currently missing. The parameter that comes closest to our needs is Bakker's (2010) classification of 
word order flexibility in European languages, which was developed as part of a large-scale project of the European Science Foundation on the "Typology of Languages in Europe."

Bakker (2010) developed a classification of 137 European languages according to different parameters, including word order flexibility, which is the parameter of interest to the current research. Bakker defines word order flexibility as the "number of word order variables that have more than one value in a language, i.e., the amount of freedom that a language has to divert from the basic order for the respective word order pairs" (p. 383). However, his classification does not only consider themerelevant criteria such as the order in which subject, object, and verb occur in sentences but also other word order regularities (e.g., whether the adjective precedes or follows the noun) that are not relevant for the scope of the present work.

Therefore, besides using Bakker's general word flexibility index in our research, we also developed a theme-specific index. Thus, we created a ranking for order flexibility that is specifically focused on the consistency with which the agent is explicitly mentioned before the recipient. Word order is one key linguistic feature that allows communicators to disentangle "who is doing what to whom," thereby allowing correct thematic role assignment. Any syntactic characteristic that allows the disambiguation of these thematic roles, makes a strict word order less necessary. To generate the theme-specific word flexibility index, we relied on the four syntactic features described above, namely, (a) the richness of verbal inflectional morphology, namely rich agreement (Bakker, 2010; Rohrbacher, 1999), (b) pronoun-drop, (c) null subject (Chomsky, 1981), and (d) the distinction of cases (Primus, 2010).

\section{Aims and Hypotheses}

In the present research we investigate the $\mathrm{SAB}$ in 14 European languages belonging to 5 different language groups (Germanic, Greek, Finnic, Romance, and Slavic). All but 3 are subject-verb-object (SVO) languages, whereas the remaining 3 languages (Dutch, German, and Greek) do not have a single predominant word order. However, in these three languages the subject-object order is preserved across multiple word orders (with only the verb migrating).

Of importance, the languages included in this study differ in their degree of word order flexibility, both according to Bakker's general word flexibility index and according to our theme-specific index defined as the sum of presence of rich agreement, of pronoun drop, of null subject and the number of cases. As can be seen in Table 1, in our sample of languages word order flexibility is highest in Finnish and in Slavic languages, both in Bakker's general and in our theme-specific word flexibility indices, although there is considerable variation within language groups.

In our study, native speakers of the 14 language communities were asked to draw two scenes (an aggression and a gift exchange) that allowed us to identify the number of times the agent was positioned to the left and the recipient to the right. We advanced two hypotheses.

First, we hypothesized that participants would show a SAB, that is an abovechance tendency to position the agent to the left of the recipient, given that all 
Table 1. Genus, canonical order of subject-object-verb, spatial agency bias model (percentage of agent to the left), Bakker's general word order flexibility index, and theme-specific word flexibility index (both continuous values and ranks) in the 14 languages

\begin{tabular}{|c|c|c|c|c|c|c|c|c|c|}
\hline Language & Genus & Canonical order & $S A B$ & $\begin{array}{c}\text { General Flexibility } \\
\text { (Bakker, 2010) }\end{array}$ & \multicolumn{5}{|c|}{ Theme specific flexibiltiy } \\
\hline French & Romance & svo & 88 & .10 & 0 & 0 & 0 & 0 & 0 \\
\hline English & Germanic & SVO & 88 & .40 & 0 & 0 & 0 & 2 & 2 \\
\hline Portuguese & Romance & svo & 72 & .30 & 1 & 1 & 1 & 0 & 3 \\
\hline Catalan & Romance & svo & 85 & .40 & 1 & 1 & 1 & 0 & 3 \\
\hline Italian & Romance & SVO & 75 & .30 & 1 & 1 & 1 & 0 & 3 \\
\hline Bulgarian & Slavic & SVO & 68 & .60 & 1 & 1 & 1 & 0 & 3 \\
\hline German & Germanic & SOV/SVO & 82 & .40 & 1 & 0 & 0 & 4 & 5 \\
\hline Greek & Greek & SVO/VSO & 68 & .60 & 1 & 1 & 1 & 3 & 6 \\
\hline Finnish & Finnic & SVO & 77 & .60 & 1 & 0 & 0.5 & 10 & 11.5 \\
\hline
\end{tabular}

Note: The number of cases was derived from WALS (Iggesen, 2013), with the exception of European Portuguese (which was missing in the WALS database). The basic word order was derived from WALS (Dryer, 2013). Pronoun drop, null subject, and rich agreement were coded by the authors based on relevant literature (Ackema, \& Neeleman, 2007; Corbett, 1983; Kaiser, 2009; Grinstead, 2000; Holmberg, 2004, 2010; Roberts, 1985; Philippaki-Warburton, 1987; Rizzi, 1986). 
languages were written from left to right and had subject-object (SO) as their predominant word order.

Second, and more important, we predicted that the more flexible the word order is in a given language, the smaller the $\mathrm{SAB}$ is likely to be.

\section{Method}

The study was preregistered at Open Science Framework (Suitner, 2018). Data and the script of the analyses are available in the same repository (Suitner, 2019).

\section{Participants}

In total, 420 volunteers participated in this study, with exactly 30 participants for each of the 14 languages (Bulgarian, Catalan, Croatian, Dutch, English, Finnish, French, German, Greek, Italian, Polish, Portuguese, Russian, and Spanish). Twenty-one participants were replaced by additional participants either because they had failed to indicate who the agent was or because they had indicated both people in the aggression scene as agents. An additional 2 participants were replaced because they knew Arabic. The final sample consisted of $68 \%$ female and $92 \%$ righthanded participants, with a mean age of $31.85(S D=13.54)$. One participant did not provide her age, and the missing data were replaced with the mean age of the entire sample. All were native speakers of the language in which they responded and were currently living in the country where the language was spoken. Participants knew between 0 and 5 foreign languages, but were unfamiliar with leftward scripts (such as Hebrew, Arabic, or Urdu).

\section{Languages, word order, and word order flexibility}

The canonical order of subject, object, and verb in 11 out of the 14 languages is SVO, whereas 2 languages (Dutch and German) have two dominant orders depending on the presence or absence of an auxiliary verb form (e.g., Laura traf ihren Freund am Bahnhof [Laura met her friend at the train station] vs. Laura hat ihren Freund am Bahnhof getroffen (Laura had her friend at the train station met), and 1 language (Greek) is classified as SVO language by Siewierska et al. (2010), but as having two dominant orders (SVO/VSO) by Dryer (2010).

\section{Bakker's general word order flexibility}

For each language we coded the degree of word order flexibility based on Bakker's (2010) classification, which constituted our primary control for the flexibility score we computed. Bakker's flexibility index derives from 10 features. The first three criteria relate to the primary elements of the clause, namely, the order of subject/ object/verb, auxiliary/verb, and verb/recipient, which are highly relevant for our hypotheses. However, Bakker's scoring also includes additional criteria referring to the flexibility with which modifiers (such as adjectives) or adverbials appear either before or after the noun, which are not relevant for our predictions. For each of the above criteria, Bakker coded whether exceptions to the canonical order are 
present or not. On this basis, Bakker computed a single flexibility score (for details see Bakker, 2010), which constituted one of the two predictors in the present research.

\section{Theme-specific word order flexibility}

We also calculated the theme-specific flexibility index using only the features that are critical for our aims, therefore for each language we coded the number of marked cases (ranging from 0 in the Romance languages up to 10 in Finnish), whether the language is characterized by rich agreement $(0-1)$, by pronoun drop $(0-1)$ and by null subject $(0,0.5$, or 1$)$. These features allow the identification of thematic roles in the sentence, making less relevant the use of order to infer who is the agent and who the recipient. An index was computed as the sum of these codes. The correlation with Bakker's general flexibility index was very high, $r=.75$, $p=.002$.

\section{Drawing task}

Participants were provided with a two-page paper questionnaire that contained the drawing task on one side and the demographic questions on the other. Our main dependent variable was the drawings that participants produced in reaction to two prompts, namely, to draw "an aggression between two people" and "the giving of a birthday gift between two people," in this order. Participants were provided with $11.7 \mathrm{~cm}$ (width) $\times 6 \mathrm{~cm}$ (height) frames in which to draw the two scenes. Instructions were purposefully provided in an abstract manner, without mentioning agent/subject or recipient/object and, hence, without priming word order. Participants were invited to produce "simple drawings that involve two people." Subsequently, they were asked to identify the agent in each drawing: "Put an A close to the person who was the attacker in your drawing." Similarly, "Put an A close to the person who gave the gift" (see Appendix A). Participants then reported demographic information (age, gender, dominant hand, nationality, profession, known languages, and extended periods abroad).

\section{Results}

\section{Spatial agency bias as a function of language and type of social interaction}

Overall, participants drew the aggression scene in $78 \%$ of the cases and the gift scene in $79 \%$ of the cases, with the agent to the left and the recipient to the right. In both cases, these percentages differed reliably from chance (50\%), binomial test, $p<.001$. Thus, in line with our first hypothesis, participants showed an overwhelming SAB, such that the agent was predominantly positioned to the left of the patient and the action evolved from left to right. This occurred despite the fact that actor and recipient were not mentioned in the instructions and, hence, no order was suggested to the participants. 
Table 2. Comparison of the tested models including Bakker's general flexibility index

\begin{tabular}{|c|c|c|c|c|c|c|}
\hline MODEL & Npar & AIC & $\mathrm{BIC}$ & $\chi^{2}$ & $\chi^{2} d f$ & $p\left(>\chi^{2}\right)$ \\
\hline M0: Null model & 3 & 858.59 & 872.79 & 4.14 & & \\
\hline M1: SAB Bakker flexibility & 4 & 852.20 & 871.14 & 8.39 & 1 & .003 \\
\hline M2: SAB Bakker flexibility + gender & 5 & 850.15 & 873.81 & 4.06 & 1 & .044 \\
\hline M3: SAB Bakker flexibility + gender + age & 6 & 846.80 & 875.20 & 5.34 & 1 & .021 \\
\hline $\begin{array}{l}\text { M4: SAB Bakker flexibility + gender } \\
\quad+\text { age }+ \text { number of known languages }\end{array}$ & 7 & 847.77 & 880.91 & 1.02 & 1 & .31 \\
\hline
\end{tabular}

$\mathrm{SAB}$, spatial agency bias.

Table 3. Fixed and random effects according to Model 3 including theme-specific flexibility (i.e., M3 of Table 2)

\begin{tabular}{lcccc}
\hline & Estimate & Std. Error & $z$ & $p$ \\
\hline (Intercept) & 1.60 & .19 & 8.31 & $<.001$ \\
\hline Theme-specific flexibility & -0.06 & .03 & -1.91 & .056 \\
\hline Gender(male) & 0.577 & .26 & 2.17 & .030 \\
\hline Age & -0.018 & .009 & -2.07 & .039 \\
\hline Random effects & Variance & Std. Dev & & \\
\hline Participants & 1.735 & 1.317 & & \\
\hline Items & 0 & 0 & & \\
\hline
\end{tabular}

\section{$S A B$ as a function of word order flexibility}

By means of the software R (R Core Team, 2016) and the package lme4 (Bates et al., 2015) we ran two separate series of generalized logistic linear mixed models fit by maximum likelihood (Laplace approximation), using as outcome variable the direction of drawings ( $\mathrm{SAB}$ congruent drawings with the agent positioned to the left vs. $\mathrm{SAB}$ incongruent with the agent positioned to the right). Participants and items (two drawings) were included as random factors, with only intercepts being allowed random variation. All numeric predictors were grand-mean centered. In 4 models (from 1 to 4 ), flexibility (either as theme-specific flexibility score or as Bakker's general flexibility index), gender, age, and the number of known languages were sequentially added to the null model (Model 0 ) as predictors of the spatial bias. The interactions between the predictors were not included as they fall outside the theoretical scope of the present research. The null model confirmed a general spatial bias, $\beta=1.78, S E=0.19, z=9.36, p<.001$, in favor of the rightward oriented drawing or image over the leftward oriented one.

In line with our hypotheses, including flexibility in the model increased the fit compared to a null model, however this was confirmed only for the Bakker's general flexibility index (see Table 2), whereas it failed to reach the statistical threshold of significance in the theme-specific flexibility (see Table 3), with $p=.07$. 
Table 4. Comparison of the tested models including the theme-specific flexibility score

\begin{tabular}{lccccccc}
\hline MODEL & Npar & AIC & BIC & $\chi^{2}$ & $\chi^{2} d f$ & $\begin{array}{c}p \\
\left(>\chi^{2}\right)\end{array}$ \\
\hline M0: Null model & 3 & 858.59 & 872.79 & & & \\
\hline M1: SAB theme-specific flexibility & 4 & 857.32 & 876.26 & 3.27 & 1 & .07 \\
\hline M2: SAB $~$ theme-specific flexibility + gender & 5 & 854.80 & 878.47 & 4.52 & 1 & .03 \\
\hline M3: SAB theme-specific flexibility + gender + age & 6 & 852.45 & 880.85 & 4.35 & 1 & .04 \\
\hline $\begin{array}{l}\text { M4: SAB } ~ \\
\text { number theme-specific flexibility + gender + age }+\end{array}$ & 7 & 853.07 & 886.20 & 1.38 & 1 & .24 \\
\hline
\end{tabular}

SAB, spatial agency bias.

Table 5. Fixed and random effects according to Model 3 including Bakker's general flexibility index (i.e., M3 of Table 4)

\begin{tabular}{lcccc}
\hline & Estimate & Std. Error & $z$ & $p$ \\
\hline (Intercept) & 1.60 & .19 & 8.42 & $<.001$ \\
\hline Bakker flexibility & -2.34 & .79 & -2.97 & .003 \\
\hline Gender (male) & 0.545 & .26 & 2.07 & .039 \\
\hline Age & -0.020 & .009 & -2.29 & .022 \\
\hline Random effects & Variance & Std. Dev & & \\
\hline Participants & 1.64 & 1.28 & \\
\hline Items & $4,98 \mathrm{E}-09$ & $7,059 \mathrm{E}-05$ & & \\
\hline
\end{tabular}

As reported in Table 2 and 4, the comparison of the four models suggests that Model 3 has the best fit, which includes also gender and age, therefore showing that language flexibility is a robust predictor of the $\mathrm{SAB}$, even when controlling for gender and age. In Tables 3 and 5 we report the fixed and random effects of Model 3 including either theme-specific flexibility score or Bakker's general flexibility index, respectively. As shown in Figure 1 and confirmed by the main effect of flexibility in both models, for both theme-specific flexibility (left panel) and Bakker's general flexibility index (right panel), SAB-congruent layouts were more frequently observed in association to lower flexibility compared to incongruent drawings. In addition, the main effects of age and gender showed that male and young participants were more likely to position the agent to left in a SAB-congruent manner, but they are beyond the theoretical scope of the present study.

\section{Discussion}

The present study confirms the SAB model across 14 languages with left-to-right writing systems, showing that speakers of European languages tend to envisage action as evolving from left to right, in line with the direction in which these languages are written and read. This attests to the cross-linguistic robustness of the 

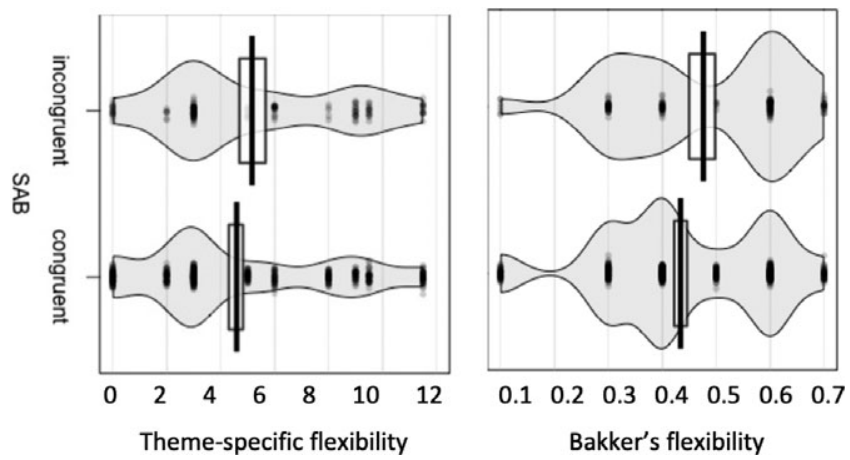

Figure 1. Pirate plots representing raw data, descriptive, and inferential statistics of theme-specific flexibility and Bakker's general flexibility index according to congruency of drawings' layout with the spatial agency bias model (SAB).

phenomenon, which, so far, had only been tested in few languages. More important, this study also shows that the magnitude of the SAB varies systematically across languages. This variability seems to reflect, at least in part, the degree to which word order is rigid or flexible in a given language. This was shown using two different flexibility indexes, namely, Bakker's general flexibility (2010) and our theme-specific flexibility index, which led to the same conclusion: the more flexible the constituent order is in a given language, the smaller the SAB. This is in line with the SAB model according to which the spatial asymmetry is the joint function of word order and script direction. Highly flexible languages such as Finnish, Polish, and Russian tend to produce smaller SABs, presumably because people are less exposed to a rigid canonical word order (including the agent-recipient order), and hence do not develop such a strong spatial schema for action.

In the present cross-linguistic study, the role of word order flexibility was investigated with two independent indices of flexibility. On the one side, the themespecific index, developed for this research, focused on language features that facilitate deviations from a rigid ordering of subject (likely to be the agent) and object (likely to be the patient), such as the presence of cases or person-number agreement. On the other side, Bakker's much more general flexibility index included a great number of "word order variables that have more than one value in a language, i.e., the amount of freedom that a language has to divert from the basic order for the respective word order pairs" (p. 383). Among these criteria were some that have nothing to do with the ordering of subject and object, such as whether adjectives always precede or follow the noun or whether their positioning may vary. Both indices influence the $\mathrm{SAB}$ in the predicted direction, but interestingly, Bakker's index was a highly significant predictor, whereas the theme-specific index was only a marginally significant predictor. If the difference is actual, it is intriguing as it suggests that it is not so much the ordering of the relevant elements (subject and Bakker's index was a highly significant predictor, whereas the theme-specific index was only a marginally significant predictor object), but rather a more general flexibility in word order that determines the strength of the SAB. At the risk of 
oversimplification, one may conclude that learning, during language acquisition, that elements of the sentence can take different positions seems more important than learning that the order of subject and object can be interchanged. This potentially opens an entirely new (and broader) research question, namely, how general word order flexibility affects imaging and possibly other cognitive processes.

Our findings also help to define an important boundary condition of the SAB. Although the SAB had previously been tested only on a limited number of languages (Italian, e.g., Carnaghi, Piccoli, Brambilla, \& Bianchi, 2014; French, e.g., Fischer, 2017; Arabic and Malagasy, e.g., Maass et al., 2014), the present study suggests that we should not expect equally robust horizontal biases in languages that have very flexible word order. Moreover, our findings suggest that the effect of word order flexibility is robust, given that a similar pattern was observed for Bakker's general flexibility index and for our theme-specific version.

Given that this is the first study investigating the role of word order flexibility in the $\mathrm{SAB}$, many questions remain unanswered at this point. One important limitation of the present study lies in the fact that it only includes some of the main European languages. To grasp the full range of word order flexibility, future studies should explore a wider range of languages within and outside of Europe, preferably including more extreme languages that show either very low (Friulian, Ladin, and Irish) or very high word order flexibility (Basque and Vepsian). A second limit regards the construction of the theme-specific flexibility index, which represents a promising yet tentative effort in need of further improvement by including additional constituents. For example, the frequency of passive voice may be considered a relevant predictor. Chatterjee, Maher, and Heilman, (1995) found a stronger SAB (left-placement of agent) when active voice than when passive voice sentences were presented. To the best of knowledge, there is no corpus that provides the relative use of passive voice across languages. Although passive voice is relatively infrequent even among languages such as English that are known to rely more on this voice (e.g., passive voice constitutes less than $10 \%$ in freshmen academic books; Moreb, 2016), the relative frequency across different languages would provide an important comparative piece of information regarding cross-linguistic differences in the prevalence of the SAB. Ultimately, the best index of the frequency of linguistic experiences where the agent precedes the recipient would be the actual frequency of agent-recipient sentences in the language (be they of any syntactic form, including actives, dislocated object, or passive sentences). Unfortunately, to date such an index is not yet available. A further issue that future studies may address regards the relative weight of the single parameters composing the flexibility index. With a parsimonious and conservative approach, we have performed a simple sum, therefore treating all parameters as if they contribute equally to word order flexibility, yet it is plausible that some parameters are more relevant than others.

Finally, the link between word order flexibility and writing direction remains underexamined. In the present study, we only included languages written from left to right. However, the SAB was specifically interpreted as the result of the combination of two factors: agent-recipient ordering and writing direction. It is therefore important to further explore this issue by investigating the role of language flexibility in leftward written languages. Related to this point, it may be worthwhile 
investigating the role of language flexibility in languages with different degrees of flexibility in written versus oral communication, such as French (Sornicola, 2006).

In sum, our study provides first evidence for the role of word order flexibility in the $\mathrm{SAB}$, which, jointly with script direction, is believed to produce asymmetrical images of human action. By identifying this underlying process, it also points to an important boundary condition for the SAB, which appears to be smaller in languages with highly flexible word order.

Finally, the subtle cultural differences that emerged in this study are in contrast with the general idea that, while words need translation, images do not. Globalized visual communication often fails to consider fine differences in how cultures envisage events through images. Further studies are needed to address the consequences of such subtleties in cross-cultural communication.

\section{References}

Ackema, P., \& Neeleman, A. (2007). Restricted pro drop in early modern Dutch. Journal of Comparative Germanic Linguistics, 10, 81.

Bakker, D. (2010). Flexibility and consistency in word order patterns in the languages of Europe. In Siewierska, A. (Ed.). Constituent order in the languages of Europe (Vol. 20, No. 1, pp. 384-419). Berlin: de Gruyter.

Bates, D., Maechler, M., Bolker, B., Walker, S., Christensen, R. H. B., \& Singmann, H. (2015). lme4: Linear mixed-effects models using Eigen and S4, 2014. R package version, 1. Vienna, Austria. URL http://www.R-project.org/

Carnaghi, A., Piccoli, V., Brambilla, M., \& Bianchi, M. (2014). Gender hierarchy in the space: The role of gender status in shaping the spatial agency bias. Journal of Social Psychology, 154, 105-114.

Chatterjee, A., Maher, L. M., \& Heilman, K. M. (1995). Spatial characteristics of thematic role representation. Neuropsychologia, 33, 643-648.

Chokron, S., \& Imbert, M. (1993). Influence of reading habits on line bisection. Cognitive Brain Research, 1 , 219-222.

Chomsky, N. (1981). Lectures on government and binding. Dordrecht: Foris.

Chomsky, N. (1995). The minimalist program. Cambridge, MA: MIT Press.

Corbett, G. G. (1983). Hierarchies, targets and controllers: Agreement patterns in Slavic. London: Croom Helm.

Dryer, M. S. (2010). Aspects of word order in the languages of Europe. In A. Siewierska (Ed.), Constituent order in the languages of Europe (Vol. 20, No. 1, pp. 283-317). Berlin: de Gruyter.

Dryer, M. S. (2013). Order of Subject, object and verb. In M. S. Dryer\& M. Haspelmath (Eds.), The world atlas of language structures online. Leipzig: Max Planck Institute for Evolutionary Anthropology.

Fischer, J. P. (2017). Character reversal in children: The prominent role of writing direction. Reading and Writing, 30, 523-542.

Grinstead, J. (2000). Case, inflection and subject licensing in child Catalan and Spanish. Journal of Child Language, 27, 119-155.

Hawkins, J. A. (1983). Word order universals: Quantitative analyses of linguistic structure. New York: Academic Press.

Holmberg, A. (2004). Null subjects and uninterpretable features: Evidence from Finnish. Unpublished manuscript, University of Durham.

Holmberg, A. (2010). Null subject parameters. In T. Biberauer, A. Holmberg, I Roberts, \& M. Sheehan, M. (Eds.), Parametric variation: Null subjects in minimalist theory (pp. 88-124). Cambridge: Cambridge University Press.

Iggesen, O. A. (2013). Number of Cases. In M. S. Dryer \& M. Haspelmath (Eds.), The world atlas of language structures online. Leipzig: Max Planck Institute for Evolutionary Anthropology. 
Kaiser, G. A. (2009). Losing the null subject: A contrastive study of (Brazilian) Portuguese and (Medieval) French. In G. A. Kaiser, \& E.-M. Remberger (Eds.), Proceedings of the workshop null-subjects, expletives, and locatives in Romance (pp. 131-156). Fachbereich Sprachwissenschaft: Konstanz Universität.

Kazandjian, S., Dupierrix, E., Gaash, E., Love, I. Y., Zivotofsky, A. Z., De Agostini, M., \& Chokron, S. (2009). Egocentric reference in bidirectional readers as measured by the straight-ahead pointing task. Brain Research, 1247, 133-141.

Maass, A., Suitner, C., Favaretto, X., \& Cignacchi, M. (2009). Groups in space: Stereotypes and the spatial agency bias. Journal of Experimental Social Psychology, 4, 496-504.

Maass, A., Suitner, C., \& Nadhmi, F. (2014). What drives the spatial agency bias? An Italian-MalagasyArabic comparison study. Journal of Experimental Psychology: General, 143, 991.

Moreb, B. (2016). The frequency of the passive voice in freshman academic books. Unpublished master's thesis, University of Central Florida.

Payne, D. L. (Ed.) (1992). Pragmatics of word order flexibility (Vol. 22). Amsterdam: John Benjamins.

Philippaki-Warburton, I. (1987). The theory of empty categories and the pro-drop parameter in Modern Greek. Journal of Linguistics, 23, 289-318.

Primus, B. 1998). The relative order of recipient and patient in the languages of Europe. Constituent Order in the Languages of Europe, $20,1$.

Primus, B. (2010). The relative order of recipient and patient in the languages of Europe. In Siewierska, A. (Ed.), Constituent order in the languages of Europe (Vol. 20, No. 1, pp. 384-419). Berlin: de Gruyter.

R Core Team. (2016). $R$ : A language and environment for statistical computing. R Foundation for Statistical Computing, Vienna, Austria. URL. https://www.R-project.org/

Rizzi, L. (1986). Null objects in Italian and the theory of pro. Linguistic Inquiry, 17, 501-557.

Roberts, I. G. (1985). Agreement parameters and the development of English modal auxiliaries. Natural Language \& Linguistic Theory, 3, 21-58.

Rohrbacher, B. W. (1999). Morphology-driven syntax: A theory of $V$ to I raising and pro-drop (Vol. 15). Amsterdam: Benjamins.

Román, A., El Fathi, A., \& Santiago, J. (2013). Spatial biases in understanding descriptions of static scenes: The role of reading and writing direction. Memory \& Cognition, 41, 588-599.

Siewierska, A., Rijkhoff, J. \& Bakker, D. (2010). Appendix-12 word order variables in the languages of Europe. In A. Siewierska (Ed.), Constituent order in the languages of Europe (Vol. 20, No. 1, pp. 783-811). Berlin: de Gruyter.

Sornicola, R. (2006). Interaction of syntactic and pragmatic factors on basic word order in the languages of Europe. In G. Bernini \& M. L. Schwartz (Eds.), Pragmatic organization of discourse in the languages of Europe (Vol. 20, No. 8, pp. 357-544), Berlin: de Gruyter.

Suitner, C. (2018). Spatial bias across languages. Preregistration retrieved from https://osf.io/v7b3c

Suitner. C (2019). Spatial bias across languages. Data file, questionnaire example and script. https://osf.io/ r5j79/?view_only=3cd97a4bc75a4367a9ce10033f4ef356

Suitner, C., \& Maass, A. (2016). Spatial agency bias: Representing people in space. Advances in Experimental Social Psychology, 53, 245-301.

Suitner, C., Maass, A., \& Ronconi, L. (2017). From spatial to social asymmetry: Spontaneous and conditioned ssociations of gender and space. Psychology of Women Quarterly, 41, 46-64. 


\section{Appendix A. English Version of the Experimental Drawing-Sheet Provided to the Participants Together with the Drawings of one Participant}

Thank you for your partecipation!

The study aims to understand how people imagine and draw social interactions.

In the boxes below, please, make simple drawings that involve two people.

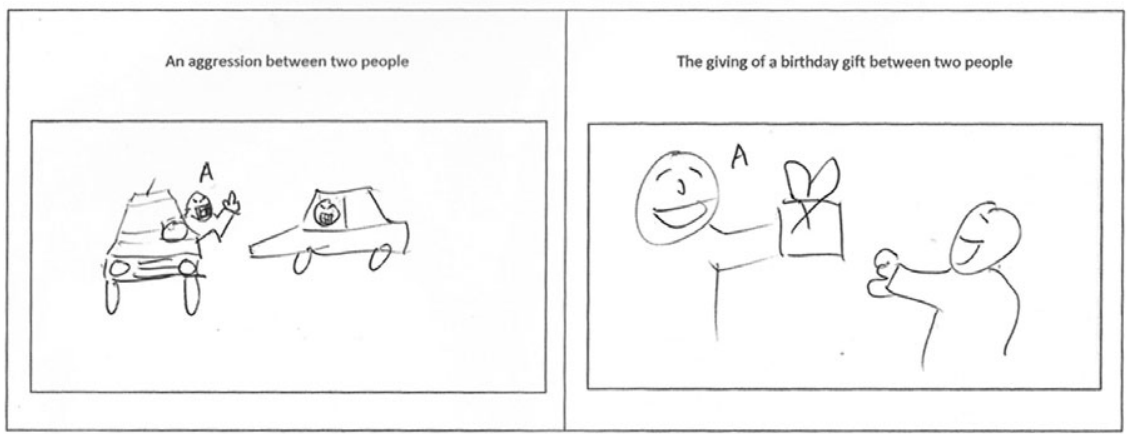

Cite this article: Suitner, C., Maass, A., Navarrete, E., Formanowicz, M., Bratanova, B., Cervone, C., Hakoköngäs, J.E., Kuppens, T., Lipourli, E., Rakić, T., Scatolon, A., Teixeira, C.P., Wang, Z., Sobral, M.P., and Carrier, A. (2021). Spatial agency bias and word order flexibility: A comparison of 14 European languages. Applied Psycholinguistics 42, 657-671. https://doi.org/10.1017/S0142716420000831 